\title{
SUCCESS FACTORS AND MEASURES FOR PUBLIC SECTOR IS/IT CO-SOURCING CONTRACTS
}

\author{
Erhan Edguer and Graham Pervan \\ School of Information Systems \\ Curtin University of Technology \\ GPO Box U1987, Perth WA 6845, Australia \\ pervang@cbs.curtin.edu.au
}

\begin{abstract}
The main objective of this research was to explore the effectiveness of contract negotiations between buyers and suppliers in small government organizations, which collectively outsource their IS/IT activities to a single outsourcing vendor, usually referred to as 'co-sourcing'. A major finding of this study was that organizations could have a successful co-sourcing arrangement by determining and putting into practice certain critical success factors. This research was the first study of government cosourcing arrangements in Australia that aimed to identify the success of a contract and the critical factors that affected it. In this regard, it can contribute to the existing body of knowledge in co-sourcing activities that have been growing rapidly in government departments as well as in the private sector.
\end{abstract}

\section{INTRODUCTION}

Outsourcing Information Systems/Information Technology (IS/IT) responsibilities has become a viable business for many companies. To ensure success, a relationship between the outsourcing vendor and the buyer that clearly defines roles and responsibilities must be developed. Proper performance measurements and well-defined service levels need to be established and monitored to achieve the desired results. However, for many organizations, measuring the performance of the outsourcer is a frustrating task. Confusion exists over what should be measured and how.

Many research studies have been conducted to inform businesses about these issues. The variety of research conducted in the area of IS/IT outsourcing includes: outsourcing types (Lacity et al. 1996), outsourcing decision-making (Gupta \& Gupa 1992), benefits of outsourcing (Galliers et al. 1999, Khosrowpour 1995), real cost of outsourcing (Ang \& Straub 1998), the role of trust in outsourcing (Sabherwal 1999), and assessing the risk of outsourcing (Aubert et al. 1998).

There is a need for empirical research to investigate government agencies that collectively outsource their IS/IT activities. This research case study was an exploratory investigation of a government IT outsourcing contract. The data collected was qualitative and the research paradigm was interpretive.

\section{BACKGROUND OF OUTSOURCING}

The outsourcing concept is not new. During the 50s, 60s and the 70s many small and medium size businesses subcontracted their information processing activities to data processing service bureaus (Khosrowpour 1995, Lacity \& Willcocks 1998), because of the high costs of purchasing and developing computer technologies. However, improvements in information technologies and wide use of personal computers made these services redundant.

In the 90s, the emergence of computer technology with communication technologies provided many organizations with new tools for the management of information and communication (Khosrowpour 1995). New global economic forces forced organizations to again find ways of reducing their costs while becoming more effective in this new competitive market. As a result, many organizations were looking for alternative ways of accessing these tools. Outsourcing was, and continues to be, one of these alternatives.

Kodak was the first large company to successfully outsource its Information Systems in 1989 and many other organizations have taken up this option. Not all outsourcing attempts have been successful and many have not reaped the benefits of outsourcing. 


\section{What is Outsourcing}

In this research, the outsourcing activity is referred to as the dynamic transition from internal provision to external provision as well as the resulting state of external provision. Therefore the definition of outsourcing used in this study is:

"IS outsourcing is the commissioning of part or all of the IS activities an organization needs, and/or transferring the associated human and other IS resources, to one or more external IS suppliers" (De Looff 1997, p.30).

Where the outsourcing is a collective arrangement between one vendor and multiple clients, the activity is referred to as "co-sourcing" (Aubert et al, 1998).

\section{Why Organizations Outsource}

Outsourcing has become an important issue for managers of information systems and technology for different reasons. Competition is becoming fiercer in national and international markets. Market shares are decreasing while global pressures are increasing. Product life cycles are getting shorter, forcing organizations to become more efficient. A shortage of skilled IS professionals places pressure on IS managers to deliver on their promise of faster, cheaper and better solutions. The reasons for organizations to outsource are many, but can be categorised under strategic focus issues, economies of scale issues, external market forces issues, and technical considerations (McFarlan \& Nolan 1995, Rothery \& Robertson 1995).

\section{When to Outsource}

Outsourcing can be justified when the IS department faces one or more of the following situations (Gupta \& Gupta 1992):

- There is immediate need to reduce costs.

- There is a critical shortage of IS talent available to continue with in-house development.

- The given IS function has no strategic advantage and an outside vendor is better suited to perform that task.

- The organization lacks suitable IS resources to respond to any sudden change in the environment to gain competitive advantage or keep up with the competitors.

- Time and talent is spent on maintaining old systems, thus preventing new developments.

- Outsourcing support functions can sharpen focus on strategic business.

- Hiring-freezes may force the outsourcing of essential IS functions.

\section{Factors in Outsourcing Decisions}

Information is defined as a strategic resource regardless of an organization's line of business (Galliers et al. 1999, Khosrowpour 1995), therefore outsourcing decisions are strategic not just operational (Gupta \& Gupta 1992). Although many organizations use outsourcing to gain a competitive advantage or decrease market pressure, outsourcing may not be right for every organization. Organizations considering outsourcing have to assess the management issues and potential problems and should perform a cost/benefit analysis as well as analysing the risks involved with outsourcing.

Common factors in outsourcing that are identified in the literature include:

- Vendor Reputation (Brewer 1998, De Looff 1997).

- Quality of Service (Tarsh 1999, Williams 1998).

- Strategic Applications (Gupta \& Gupta 1992, Khosrowpour 1995).

- Loss of IS Positions (De Looff 1997, Khosrowpour 1995).

- Demoralised Employees (Gupta \& Gupta 1992).

- Untested Waters (Gupta \& Gupta 1992, Rothery \& Robertson 1995).

- Loss of Control (McFarlan \& Nolan 1995, Rothery \& Robertson 1995).

- Cost Benefit Analysis (De Looff 1997, Khosrowpour 1995). 


\section{Outsourcing in Government}

The outsourcing of IT is not limited to the private sector and most government organizations outsource some or all of their IS/IT. Major factors contributing to the trend towards government outsourcing include: tighter budgets, lack of specialised skills among government employees, and politicians' discontent over spending on botched IT programs (Anonymous 1996).

A 1993 study of businesses and government agencies by Penton Research Services showed that 44\% of the executives surveyed said they are doing more outsourcing than they did 5 years before, and $47 \%$ said they expected to increase the amount of work they outsourced by the year 2000 (Kelley 1995). As outsourcing has grown in the last few years, so has its scope.

Government organizations are going through the same processes as their private counterparts. The success of outsourcing in government departments also depends on how they negotiate their outsourcing contracts with vendors. However, there is very little research done in the area of outsourcing IS/IT in government organizations, especially those that collectively outsource their IS/IT to a large vendor.

\section{RESEARCH QUESTION AND APPROACH}

The outsourcing literature has clearly identified a rapid increase in outsourcing arrangements across the business sector for many different reasons. With the increase in outsourcing arrangements a number of issues have been identified that affect these outsourcing arrangements. Whether outsourcing is total or selective, these issues affect the business. Many research studies have been conducted to inform organisations about these issues, but analysis of the literature suggests that there has been little research done in the area of (a) co-sourcing contracts, (b) government IT outsourcing, and (c) co-sourcing contract negotiations.

Therefore this study is focused on these areas of outsourcing identified above and. investigates the following research questions:
a) What are the objectives of government agencies that collectively outsource selected IT functions?
b) How successful are co-sourcing contracts?
c) How do government agencies measure the success of the contract?
d) What critical success factors determine the success of the contract?
e) What other factors contribute to the success of the contract?

This study aims to explore the co-sourcing arrangements within government agencies and illustrate the issues involved by answering the above questions.

\section{Selection of the Research Method}

The selection of a research method depends on the purpose of the research and context of the research question. Galliers (1991) proposed a taxonomy to assist IS researchers to match research method to objectives. Given the above questions, the research is focused on organizations (not individuals or groups), on methodology (not technology), and on theory building (not testing or extension), so clearly the case study approach can be considered suitable.

\section{Research Design}

Given the exploratory nature of the case, data collected was mostly qualitative and the research paradigm interpretive. Data was collected in the six government agencies (referred to as Agency A ... F) that were part of a consortium that signed a co-sourcing agreement with an outsourcing service provider, in the government agency responsible for contract negotiation and management, and from the provider. The core data was obtained by interview and document review. 


\section{Interview}

Semi-structured interviews were conducted with two people responsible for the contract management at each of the six agencies (one at the strategic level and the other at the contract management level). The twelve interviews were tape-recorded, transcribed, emailed to the interviewee for accuracy checking, and corrected. Approximately 150 pages of transcripts were then analysed.

\section{Document Review}

The second source was a document review, which was used to investigate several organizational issues within the chosen organizations and to provide a means of triangulating the data (McFarlane 1998). The documents collected and analysed included (a) the head contract and service agreement, (b) contract promotional material, and (c) web sites of the agencies.

\section{DISCUSSION OF FINDINGS}

The findings presented here are based on a content analysis of all of the data described above. Thirteen success measures were identified in the analysis and the managers agreed that, overall, the contract successfully delivered services according to the levels negotiated and defined in the service agreements. The analysis also identified thirteen critical success factors that the managers believed had positively contributed to the success of their co-sourcing contract. These success measures and factors are listed in Table 1 below. Brewer (1998) suggested that organizations had to identify critical success factors to succeed in their outsourcing arrangement. Perigo (1998) identified that government departments in the UK used critical success factors such as 'departments made the outsourcing decision to meet their business needs' to ensure successful outsourcing contracts.

Further analysis of the data collected established a relationship between the success measures and the critical success factors identified by the agency representatives. These relationships were vital to the measure of success in the contract and are presented in Table 2 below.

\begin{tabular}{|c|c|}
\hline 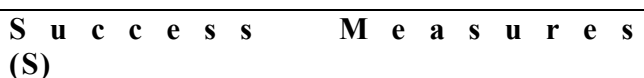 & $\begin{array}{l}\text { Critic a l S u c e s s F a c tors } \\
\text { (F) }\end{array}$ \\
\hline $\begin{array}{l}\text { 1. } \text { decrease the staff numbers } \\
\text { 2. establish continuity within the IS } \\
\text { 3. focus on the core business } \\
\text { 4. reduce costs and manage assets efficiently } \\
\text { 5. better compete in the market } \\
\text { 6. increase productivity } \\
\text { 7. clear operational processes } \\
\text { 8. reduce or control operating costs } \\
\text { 9. access world-class leading-edge technology } \\
\text { 10. access to skilled IT professionals } \\
\text { 11. implementation of emerging technologies } \\
\text { 12. looking for a strategic partner for IT services } \\
\text { 13. compliance with service level agreements }\end{array}$ & $\begin{array}{l}\text { 1. meet the business needs } \\
\text { 2. involved staff in the process } \\
\text { 3. clear understanding } \\
\text { 4. tracked the performance } \\
\text { 5. understood costs performance and quality } \\
\text { 6. communicated regularly and openly } \\
\text { 7. flexible contracts } \\
\text { 8. transparent transition to new provider } \\
\text { 9. addressed problems, constructive not } \\
\text { defensive } \\
\text { 10. understood responsibilities and obligations } \\
\text { 11. service provider is proactive } \\
\text { 12. problems resolved at an appropriate level } \\
\text { 13. continually review arrangements }\end{array}$ \\
\hline
\end{tabular}

Table 1: List of Success Measures and Critical Success Factors 


\begin{tabular}{|c|c|c|c|c|c|c|c|c|c|c|c|c|c|}
\hline & F1 & F2 & F3 & F4 & F5 & F6 & F7 & F8 & F9 & F10 & F11 & F12 & F13 \\
\hline S1 & $\mathbf{X}$ & & $\mathbf{X}$ & & & & & & & & & & \\
\hline S2 & & & & $X$ & & & & & & & & $X$ & $X$ \\
\hline S3 & $\mathbf{X}$ & & & & & & $\mathbf{X}$ & & & & $\mathbf{X}$ & & $\mathbf{X}$ \\
\hline S4 & $\mathbf{X}$ & & $\mathbf{X}$ & $\mathbf{X}$ & & & $\mathbf{X}$ & & & & $\mathbf{X}$ & & $\mathbf{X}$ \\
\hline S5 & $\mathbf{X}$ & & $X$ & $\mathbf{X}$ & & & $X$ & & & & $\mathbf{X}$ & & $\mathbf{X}$ \\
\hline S6 & $\mathbf{X}$ & & & & & & $\mathbf{X}$ & & & & $\mathbf{X}$ & & $\mathbf{X}$ \\
\hline S7 & $\mathbf{X}$ & $\mathbf{X}$ & $\mathbf{X}$ & & & & & & & $X$ & & $\mathbf{X}$ & \\
\hline 58 & $\mathbf{X}$ & & & $\mathbf{X}$ & $X$ & & $\mathbf{X}$ & & & & $\mathbf{X}$ & & $\mathbf{X}$ \\
\hline S9 & $\mathbf{X}$ & & & & & & $\mathbf{X}$ & & & & & & $\mathbf{X}$ \\
\hline $\mathbf{S 1 0}$ & $\mathbf{X}$ & & & $\mathbf{X}$ & & & & & & & $X$ & & $\mathbf{X}$ \\
\hline S11 & $\mathbf{X}$ & & & & & & $X$ & & & & $\mathbf{X}$ & & $\mathbf{X}$ \\
\hline S12 & $\mathbf{X}$ & & $X$ & & & & $X$ & & & & & & \\
\hline S13 & $\mathbf{X}$ & $\mathbf{X}$ & $\mathbf{X}$ & $\mathbf{X}$ & $X$ & $\mathbf{X}$ & $\mathbf{X}$ & $\mathbf{X}$ & $\mathbf{X}$ & $X$ & $\mathbf{X}$ & $X$ & $\mathbf{X}$ \\
\hline
\end{tabular}

Table 2: Relationship between Success Measures and Critical Success Factors

The analysis established that success measures S1, S2, S9, and S12 were affected by less than four CSFs, while the others were affected by more than four. The least number of CSFs contributed to S1 (decrease staff numbers) and the most CSFs contributed to S13 (compliant with service level agreement). Thus, S13 may be considered a major success measure for the contract and S1 less important.

The analysis also identified that while some CSFs (F2, F5, F6, F8, F9, F10, and F12) contributed to less than four success measures, others (F1 (12), F7 (9), and F13 (10)) contributed to many more success measures. This implies that F1, F7, and F13 are the most important CSFs, contributing to most success measures.

The research study also identified that all the agencies judged their performance by how much they achieved their objectives, a finding supported elsewhere (Brewer 1998, Gupta \& Gupta 1992, McFarlane 1998). The thirteen success measures will now be discussed in some detail.

\section{Decrease Staff Numbers to Reduce Expenditure (S1)}

Decreasing staff numbers to meet business needs was achieved by all the agencies through staff reductions in their IS departments. All the agencies acknowledged the effect of the change of their IS department's role in their organization. Most of the staff went to work for the outsourcing service provider. This created immediate savings to the agencies through the reduction in the salaries paid to staff.

\section{Establish Continuity within the IS activities (S2)}

Establishing continuity within the IS activities was achieved by all the agencies through the contract they signed with the outsourcing vendor. The contract had certain clauses to protect the agencies from the vendor going into liquidation or not meeting the contract service levels. Money was deposited in a trust account to compensate the agencies and assist them to switch to another vendor if necessary. Also, agency A kept the ownership of its equipment and only outsourced its services.

\section{Focus on the Core Business (S3)}

Focusing on their core business was a very important success measure and a major objective of the agencies in outsourcing their IS functions. The agencies achieved this at different levels. While Agencies A, C, and E were experiencing difficulties with their service provider's delivery, the others recognised that they were able to focus on their core business after the outsourcing arrangement. This could be related to the agencies' views on the critical success factors that affected this success measure. Agencies A, C, and E were all concerned that their service provider was not being proactive in advising them in their business decisions. Others were quite happy with the service 
provider's actions. This finding is supported by Gupta and Gupta (1992) who suggest that outsourcing their IT functions could enable the organizations to focus more on their core business and leave IT delivery to the outsourcers.

\section{Reduce Costs and Manage Assets More Efficiently (S4)}

Reducing costs and managing assets more efficiently was identified as being achieved with some aspects of the arrangement. All agencies agreed that cost reduction in hardware and software licences was achieved in the first three years of the contract but in the long run there were no cost savings. Lacity and Willcocks (1996) confirm this and suggest that organizations could reduce their IT operating costs by selectively outsourcing their IT functions for a limited period.

\section{Enable the Organization to Better Compete in the Market (S5)}

Brewer (1998) suggests that market forces could force an organization to resort to outsourcing and, by the outsourcer running this support function more efficiently, create a competitive advantage. This may not be case in government organizations as they usually don't compete with other organizations in delivering goods and services in the market place. Only Agency D, with a different corporate structure and culture than the other government agencies, acknowledged the importance of this measure.

\section{Increase in Productivity (S6)}

Most of the agencies claimed they achieved increased productivity through outsourcing. This was said to be facilitated by the service provider's buying power and ability to use more efficient managerial processes. However, A and E said that they did not achieve the expected increase in productivity, perhaps because their expectations were too high. The other four agencies had more realistic expectation on their productivity improvement. Jones (1997) supports this and suggests that outsourcing activities that are not core competencies allows companies to focus attention on areas that add the most value.

\section{Clear Operational Processes (S7)}

Four agencies (B, C, E, F) indicated that they achieved clearer operational processes through their outsourcing arrangement. This could be explained by their ability to respond to the changes made to their business procedures. They all believed that outsourcing enabled the processes to be more simple and accountable. Agency A and D both claimed that the processes did not achieve any major improvements perhaps because they had problems adjusting to the new system.

\section{Reduce or Control Operating Costs (S8)}

Reducing or controlling operating costs was an important success measure. One of the research outcomes was that the agencies were able to control and reduce operating costs through the contract. The outsourcing vendor could create economies of scale and deliver the same services more efficiently and cheaply through the ability to access bigger markets using the same infrastructure in similar contracts. All the agencies acknowledged that there was a significant cost saving in services delivered by the outsourcing vendor. However, all the managers interviewed said that these savings were only short term. This could be because the vendor also has to pay for new staff and new infrastructure as well as trying to deliver the services. Lacity et al. (1996) suggest that organizations could reduce their IT operating costs by selectively outsourcing their IT functions for a limited period. 


\section{Access World-class Capabilities and Leading-edge Technology (S9)}

Accessing world-class capabilities and leading edge technology was another success measure the agencies wanted to achieve. All said that their decision to outsource included the areas of networking, which incorporated helpdesk as well as LAN and WAN support, and SAP application development. Agency E claimed that it was impossible for them to in-source their new application development and also support the resources needed to implement this new business application, so the management decided to outsource the whole applications and network administration to the outsourcing vendor. Agency F held the view that the outsourcing service provider had been successful in delivering the outsourced applications overall, but Agency E had the opposite view on networking and remote logins. The reason for this could be that the relationship between the agency $\mathrm{F}$ and the vendor was very good. The dissatisfaction also could be due reasons such as lack of understanding, the current infrastructure, early days of the contract, the network being effected by factors outside the agency, and lacking a good relationship between two parties. Further analysis of the data revealed that the relationships were more harmonious where the agencies had been more selective in the IT functions outsourced. Gupta and Gupta (1992) suggested that one of the reasons for many organizations to outsource was to gain access to the outsourcing vendor's capability of providing access to the leading-edge technologies.

\section{Access to Skilled IT Professionals (S10)}

Accessing skilled IT professionals through the outsourcing decision was very important. The agencies all had the problem of not being able to recruit skilled IT professionals due to their staffing and salary arrangements. Agency F claimed that they previously had to employ the particular skilled professionals they needed from a contracting company, had to pay twice the amount of a reasonable IT salary for their services, and only employed them for a short period on a needs basis. All the agencies agreed they gained access to a wide range of skilled professionals through their outsourcing service provider. They claimed that it was very hard to run certain applications without an outsourcing vendor because they would not have all the right skilled people available in-house. The outsourcing arrangement helped the agencies to access a pool of IT staff that was provided by the outsourcing vendor. However, A and C suggested that it wasn't always easy to access this pool of staff but it was there if the agency urgently needed them. This could be explained as the source being scarce but available when needed, according to the priority of the work to be conducted. Brewer (1998) argued that outsourcing would assist organizations with addressing their resource constraints and skill shortages.

\section{Implementation of Emerging Technologies (S11)}

Implementing emerging technologies through outsourcing was another success measure. Prior to their outsourcing decision, all the agencies had concerns over their inability to use emerging technologies. All the agencies believed that outsourcing would give them the opportunity to access these new and flexible technologies. The analysis revealed that the agencies did gain access to emerging technologies through their outsourcing arrangement. They all claimed that their platform changes were assisted and implemented by their outsourcing vendor during major infrastructure changing processes, such as switching from a mainframe to a networking environment. This could be attributed to the ability of the outsourcing vendor to provide the right skilled staff and the infrastructure. Gupta and Gupta (1992) argued that technical considerations push companies towards outsourcing their information systems needs rather than meeting them in-house.

\section{Looking for a Strategic Partner for IT Service (S12)}

All managers interviewed agreed that the open-book type strategic partnership agreement had been their objective. The managers claimed that the current contract was an open-book strategic partnership agreement and was quite successful overall. The agencies had regular meetings at two different levels with the outsourcer: 
- Contract management level - where the contract managers had regular monthly meetings. They openly and collectively discussed unresolved issues with the account manager from the outsourcer.

- Strategic management level - where the Information managers and heads of IS departments came together every second month and discussed the unresolved issues and contract outcomes with a senior executive from the outsourcing vendor.

All of the agencies commented on the importance of these regular meetings, and suggested that they were positively contributing to the success of the contract. The managers interviewed all acknowledged that this mechanism was there to keep the negotiations in place and help both parties to solve problems that couldn't be solved by the staff at a technical level on a daily basis. It was suggested that this mechanism was in place as a result of the partnership approach towards their outsourcing arrangement adopted by both sides. Marcolin and McLennan, (1998) suggest that relationships are very important to the success of any outsourcing decision and concluded that their research on effective IT outsourcing arrangements demonstrated that the organizations with strategic partnerships were more successful in their arrangement than the buyer/seller type of outsourcing. This may be the case for government agencies as well as in the private sector.

\section{Compliance with Service Level Agreements (S13)}

Complying with the service level agreements was a very important success measure for all of the agencies. The strategic-level management of the organizations addressed the measurement of the performance of their outsourcing vendor by evaluating how much they complied with their service level agreements. Lacity and Hirschheim (1995) suggested that in order to complete the contract, service levels, cost structures and penalties for non-performance must be specified and agreed to by both parties. Service level agreements play a major role in outsourcing contracts. Arnold and Butler (1995) also argue that it is normal for a contract to include provision that the supplier will provide the services by meeting the service levels identified in the schedules. They also further suggest that since a commercial relationship exists between the parties, the schedules have to identify what performance levels and standards are required. Lacity and Hirschheim (1995) also pointed out that identified service levels have to be subject to continuous monitoring and formal periodical review by the parties.

\section{Other issues}

The study also discovered that the agencies were affected by the outsourcing decision at different levels. For example while one of the agencies (E) suggested that the effect of the outsourcing decision on its IS department was minimal, the other five agencies described the effects from being devastating to substantial. They all measured the effect by the reduction in IS personnel in their agency. However, E already had a contractual relationship with a service provider for its payroll system and in-house IS service delivery was already minimal. The other agencies didn't have prior outsourcing arrangements and relied heavily on in-house IS service delivery.

The study also identified that different agencies within the consortium had different views over the service provider's performance. While B, D, and F described the service provider's performance as very good, the other agencies claimed that they had several major problems with the service provider. This could be attributed to the different agencies attitudes towards the outsourcing service provider and also the degree of selectiveness of the outsourcing. Another reason could be that the government had pressured some to outsource their IT functions. The agencies that said that outsourcing was totally their decision, regardless of government pressure, and (despite the problems mentioned above) confirmed that they were very happy overall with the service provider's performance.

Another important issue pointed out by a manager from Agency E was the reporting mechanism that the agency had to deal with. It was claimed that the service provider provided the agency with regular reports of what they have done. By the time the management read and act upon this report it was two months old. During the interview this manager said "We are coming to the end of September, we will almost be in November when we receive the September report, so the validity of 
the information we are dealing with becomes a bit grey. We recall from our memory that the issues are valid but it looses a quite a bit of its meaning". Clearly, internal procedures have to be reengineered to gain maximum leverage from these arrangements.

\section{SUMMARY AND CONCLUSION}

Outsourcing has become a popular business strategy being implemented by private and government organizations. Varied research has been conducted to evaluate the benefits and risks involved in outsourcing. However, most of the studies done in this area have been carried out in the private sector, and very little published work has been conducted in the government sector. This study aimed to explore the effects of contract negotiations between the buyers and suppliers towards their success in government organizations.

While there were some time and resource limitations for this case study, it did reveal that cosourcing contracts could be successful. This success could be measured in a number of ways and some thirteen different measures of success were revealed for these co-sourcing arrangements and were generally supported by past research which had been applied to investigating other outsourcing arrangements. This success was dependent on particular critical factors being identified and implemented correctly. Some thirteen of these critical success factors were identified from the analysis and these were associated in varying degrees with some thirteen success measures. While many of these factors and measures are supported by previous research, most of this has been conducted in the private sector and this study confirms what the relevance of different factors and measures in a public sector IT outsourcing environment. In particular, this research fills a gap for the situation where the outsourcing is a multi-client, single-vendor (co-sourcing) arrangement.

\section{REFERENCES}

Anonymous. (1996) “Outsourcers," Government Executive, Vol. 28, No. 11, pp. 42-44.

Ang, S. \& Straub, D. W. (1998) "Production and Transaction Economies and IS Outsourcing: A Study of the U.S. Banking Industry," MIS Quarterly, Vol. 22, No. 4, pp. 535-552.

Arnold, C. \& Butler, R. (1995) Outsourcing Contracts: A Specially Commissioned Report, Pearson Professional Ltd, London.

Aubert, B., Patry, M. \& Rivard, S. (1998) “Assessing the risk of IT outsourcing," Proceedings of the $31^{\text {st }}$ Annual Hawaii International Conference on System Sciences, Hawaii, January 5-8, pp. 685-692.

Brewer, R. (1998) "Understanding what outsourcing is and is not and what this will mean to your business or organization," Proceedings of Second Wave Outsourcing and Service Level Agreements in IT, Business Law Education Centre, Sydney, pp. 1-44.

De Looff, L. (1997) Information Systems Outsourcing Decision Making: A Managerial Approach, Idea Group Publishing, London.

Galliers, R.D. (1991) "Choosing Appropriate Information Systems Research Methodologies," in Nissen, H.E., Klein, H.K., \& Hirschheim, R. (Eds.) Information systems research: Contemporary Approaches and Emergent Traditions, New-Holland, Amsterdam, pp. 327346.

Galliers, R. D., Leidner, D.E. \& Baker, B.S.H. (1999) Strategic Information Management: Challenges and Strategies in Managing Information Systems, $2^{\text {nd }}$ ed., ButterworthHeinemann, Oxford.

Gupta, G. \& Gupta, A. (1992) "Outsourcing the IS Function: Is it Necessary for Your Organization?" Information Systems Management, Vol. 9, No. 3, pp 44-50.

Jones, W. (1997) "Successful Outsourcing", CIO Perspective Conference: Core Competencies and Competitive Advantage, October 12-15, Online Available: http://www.cio.com/conferences/1097 concurrent c.html .

Kelley, B. (1995) "Outsourcing Marches On,” Journal of Business Strategy, Vol. 16, No. 4, pp. $38-42$.

Khosrowpour, M. (1995) Managing Information Technology Investments with Outsourcing, Idea Group Publishing, London. 
Lacity, M.C. \& Hirschheim, R. (1995) Beyond The Information Systems Outsourcing Bandwagon: The Insourcing Response. John Wiley \& Sons Ltd, England.

Lacity, M. \& Willcocks, L. (1996) "Interpreting Information Technology Sourcing Decisions From A Transaction Cost Perspective: Findings and Critique," Accounting, Management \& Information Technology, Vol. 5, No. 3/4, pp. 203-244.

Lacity, M. \& Willcocks, L. (1998) “An Empirical Investigation of Information Technology Sourcing Practices: Lessons from Experience,” MIS Quarterly, Vol. 22, No. 3, pp. 363-408.

Lacity, M., Willcocks, L. \& Feeny, D. (1996) "The Value of Selective IT Sourcing," Sloan Management Review, Spring, pp. 13 - 25.

Marcolin, B.L. \& McLellan, K.L. (1998) "Effective IT Outsourcing Arrangements," Proceedings of the $31^{\text {st }}$ Hawaii International Conference on the Systems Sciences, Hawaii, January 5-8, pp. 654-665.

McFarlan, F. W. \& Nolan, R.L. (1995) "How to Mange an IT Outsourcing Alliance", Sloan Management Review, Winter, pp. 9-23.

McFarlane, P. (1998) "Managing the relationship with the service provider," Proceedings of Second Wave Outsourcing and Service Level Agreements in IT, Business Law Education Centre, Sydney, pp. I-VI.

Neuman, W.L. (2000) Social Research Methods: Qualitative and Quantitative Approaches, $4^{\text {th }}$ ed., Pearson Education, USA.

Perigo, J. (1998) "Critical Success Factors In IS/IT Market Testing and Outsourcing.," Available [online]: http://policyworks.gov/org/main/mg/intergov/letter/Perigo.html.

Rothery, B. \& Robertson, I. (1995) The Truth About Outsourcing, Gower Publishing Limited, England.

Sabherwal, R. (1999) "The Role Of Trust In Outsourced IS Development Projects", Communications of The ACM, Vol. 42, No. 2, pp. 80-86.

Tarsh, S. (1999) "Managing the Outsourcing Relationship: A Shared Vision Produces Greater Rewards," Available [online] http://www.outsourcing-search.com/resources.html .

Williams, O. (1998) Outsourcing. A CIO's Perspective. St. Lucie Press, Ohio. 